\section{AINA NEWS}

\section{CropBox at Kluane Lake Research Station}

CropBox is a containerized agriculture system that uses hydroponic technology to grow up to $18000 \mathrm{lbs}$. of fresh produce. With automated lights, $\mathrm{PH}$ levels, heating and $\mathrm{CO}_{2}$, the CropBox can reduce growing times and provide year-round produce in any climate. Our system is all about efficiency, using $90 \%$ less water and $80 \%$ less fertilizer than conventional agriculture methods and produces some of the best produce out there. These systems are designed with harsh conditions in mind and can come with R60 insulation and an Arctic Entrance to provide more space to harvest and package produce.

We propose to install and evaluate the food production capabilities, economic feasibility, environmental sustainability, and optimized operating settings of an offgrid, cold-weather adapted, containerized food production system at the Kluane Lake Research Station in Yukon Territory (Fig.1). Containerized agricultural systems offer much promise given other initiatives that have tested a similar model in other geographies. This proposed project will be the first time that such a system will be operated completely off-grid, using predominantly solar energy. As containerized food production systems were first developed in warmer climates, we are also testing the effectiveness of a cold-weather adaptation (via an insulating sleeve) for the first time to test its ability to optimize energy usage in subarctic temperatures.

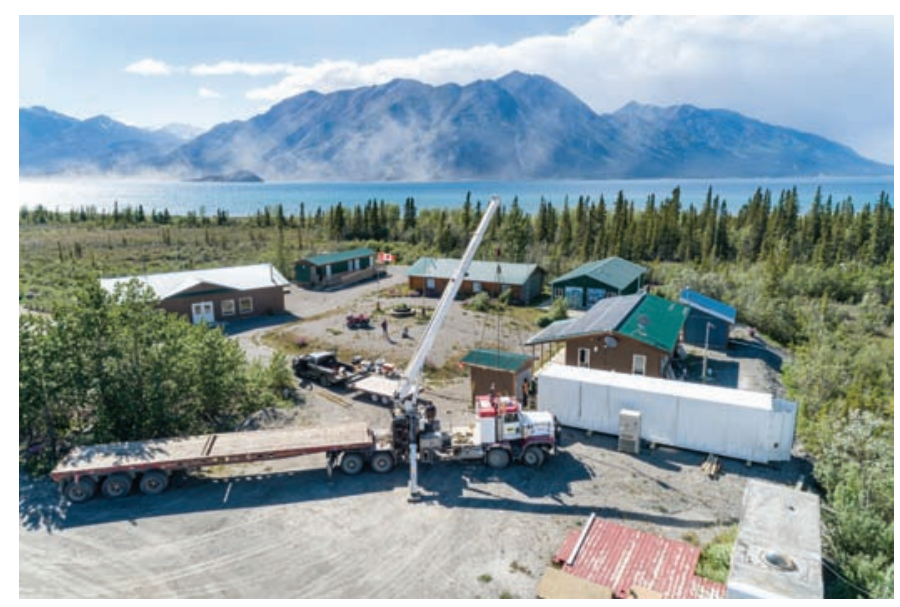

FIG. 1. Installation of the Cropbox at the Kluane Research Station.

This project will test and potentially make the case that off-grid containerized agricultural systems offer a long-term sustainable approach to food production in remote northern locations. This proposed experiment will test, monitor and evaluate variables in order to help communities make informed decisions about investing in similar technologies. Examples of variables that will be tracked include: water use, renewable energy storage and consumption, food production, and the nutritional quality of food produced across a seasonal gradient. Economic feasibility is an important consideration, and we will evaluate if produce can be grown in an off-grid containerized agriculture system for less than the cost of purchasing fresh produce (including transportation) of a comparable quality from Whitehorse. More specific economic considerations will include: actual versus estimated costs to purchase, install, and operate the specialized system; human resource requirements to manage the system; volume and costs of inputs (seeds, plants, water, fertilizer); volume of diesel required to supplement the off-grid system; and comparative cost to run the system on-grid versus off-grid to name a few examples.

The seeds are planted into dirt-free compostable squares, these are then placed under specialized grow lights to get the seedlings started (Fig. 2). Depending on the germination time for the specific plant they could be in this process from a couple of days to a couple of weeks. Once the seedlings have started to sprout they are moved from the nurturing station to their own space within the CropBox where they will grow until harvest. Depending on the plant, this takes $1-4$ weeks to produce crops such as spinach, lettuce, kale, strawberries, and arugula. Harvesting is as simple as pulling the plant out and cutting off the bottom compostable square. Without any dirt, this process is clean and quick. You are now ready to enjoy your produce, and use that space again.

This project has a number of partners including the

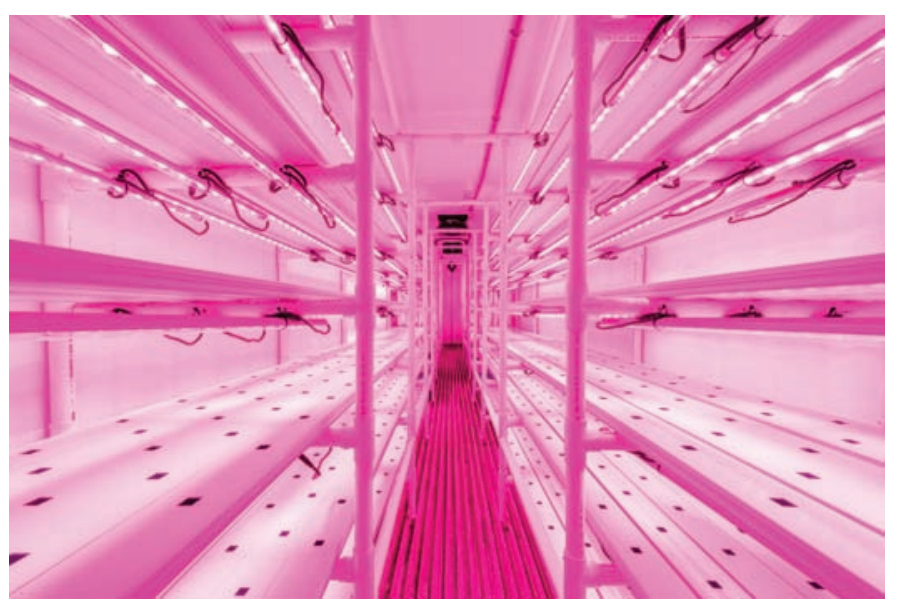

\section{FIG. 2. Cropbox interior and lighting.}

Arctic Institute of North America, University of Calgary, Kluane Lake Research Station, and Kluane First Nation. These partners are joined by ColdAcre Food Systems Inc. out of Whitehorse who are growers, builders, designers, consultants, and suppliers of innovative and sustainable growing systems for fresh and nutritious food year-round, and Solvest Inc. (Whitehorse), a solar company specializing in northern residential, commercial, and utility-scale solar installations. 


\section{Narwhal Tusk Donated to the AINA Collection through Goodwill}

Since a narwhal tusk was dropped off at one of Calgary's Goodwill donation centres in September, it has been re-homed at the Arctic Institute of North America. The $60 \mathrm{~cm}$ long narwhal tusk, complete with Canadian federal hunting tags from 1978, has been gifted to AINA by Goodwill Industries of Alberta to reside permanently in the AINA collection (Fig. 3).

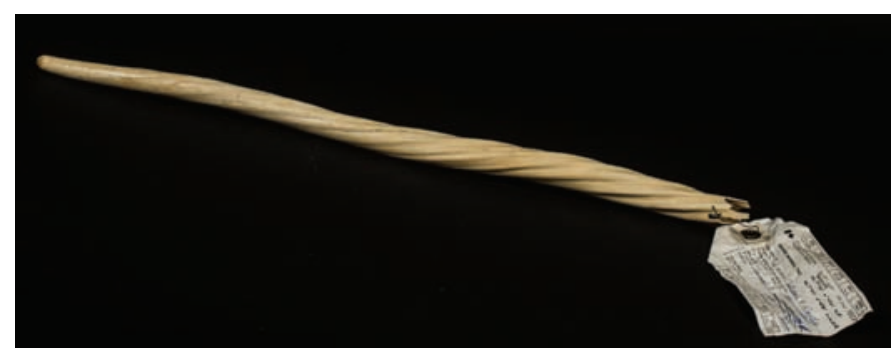

FIG.3. Donated narwhal tusk (Photo credit: Hesam Rezaei).

A narwhal tusk is a protruding, spiral canine tooth that can grow to $3 \mathrm{~m}$ and has up to 10 million nerve endings inside. Their exact purpose is not known, but scientists believe that tusks are used for hunting or mating purposes.

The mysterious mammals are a protected species, and the harvesting and sale of their tusks is managed by the communities of the high Arctic and the Canadian government. There are no narwhals in captivity, so tusks are the closest that most people will get to seeing a 'unicorn of the sea' in person.
"The tusk was collected by an Inuk while hunting, likely primarily for food," says Dr. Sandie Black, PhD, clinical associate professor in the Faculty of Veterinary Medicine and head of veterinary services at the Calgary Zoo. "Narwhal maqtaq - skin and a small amount of blubber - is an important food energy source for many communities."

Black believes the tusk is from a young narwhal, approximately 3-5 years of age. "The tusk represents an opportunity for cash income when sold," she says. "Tusks are a platform for artistic expression in modern Inuit communities and are carved by craftspeople in the community to be sold through art cooperatives or other outlets."

The tusk was donated anonymously, like many unique objects that are given to Goodwill donation centres. While the intention of the donor is not known, Goodwill wished to give the tusk to an organization that would preserve its historical and cultural integrity. "This is a way to create an educational opportunity in our community based on historical, environmental, and cultural significance. We are proud to work with the Arctic Institute of North America to feature higher learning of what the narwhal means to those living in the Arctic," says Dale Monaghan, CEO of Goodwill Industries of Alberta.

AINA maintains a large collection of Arctic art and artefacts used in its educational, outreach, and online programming. "Our collection did not previously include a narwhal tusk and we are excited to receive this specimen from Goodwill," says Shannon Christoffersen, manager of Data and Information Services, AINA. "We look forward to including it in our educational exhibits and programming to help others learn more about the Canadian Arctic." The narwhal tusk was handed off to AINA in a closed celebration in November. 